\title{
Plantas alimentícias não convencionais produzidas no sul de Minas Gerais
}

\author{
Non-conventional vegetables produced in the south of Minas Gerais \\ Plantas no convencionales producidas en el sur de Minas Gerais
}

Recebido: 27/12/2021 | Revisado: 01/01/2022 | Aceito: 11/01/2022| Publicado: 13/01/2022

\author{
Nilton de Oliveira Silva \\ ORCID: https://orcid.org/0000-0003-2794-3001 \\ Universidade José do Rosário Vellano, Brasil \\ E-mail: nilton.silva@emater.mg.gov.br \\ Luis Felipe Lima e Silva \\ ORCID: https://orcid.org/0000-0002-6082-9182 \\ Universidade José do Rosário Vellano, Brasil \\ E-mail: luis.silva@unifenas.br \\ Andressa Santanna Natel \\ ORCID: https://orcid.org/0000-0002-7032-1606 \\ Universidade José do Rosário Vellano, Brasil \\ E-mail: andressa.natel@unifenas.br \\ Hudson Carvalho Bianchini \\ ORCID: https://orcid.org/0000-0002-3531-8233 \\ Universidade José do Rosário Vellano, Brasil \\ E-mail: hudson.bianchini@unifenas.br \\ Adriano Bortolotti da Silva \\ ORCID: https://orcid.org/0000-0003-1316-8243 \\ Universidade José do Rosário Vellano, Brasil \\ E-mail: adriano.silva@unifenas.br
}

\begin{abstract}
Resumo
As plantas alimentícias não convencionais (PANC) representam grande importância e potencial produtivo crescente, sendo importante a identificação das espécies em cada região. Neste sentido, objetivou-se identificar e quantificar variáveis que caracterizassem os sistemas de produção de diferentes espécies de PANC na região Sul de Minas Gerais. Foi utilizada uma amostra de grupo representativo com 96 produtores selecionados entre 12 associações, referente ao período de 2018 a 2019. Foram catalogadas 35 espécies de PANC produzidas em área total de 138 hectares, sendo Inhame-Taro (Colocasia esculenta), Alho Poró (Allium porrum), Ora-Pro-Nóbis (Pereskia aculeata), Cará-do-ar (Dioscorea bulbifera), Guandu em grão (Cajanus cajan), açafrão (Curcuma longa), Gengibre (Zingiber officinale), Espinafre (Spinacea oleracea), Batata Yacon (Smallanthus sonchifolius), e Serralha (Sonchus oleraceus), as espécies mais representativas em área produzida com essas espécies (64\%). A associação Camponesa, de Campo do Meio-MG, representou a maior produtora de plantas alimentícias não convencionais (30\% do total de PANC comercializadas). Houve uma tendência de aumento no número de produtores com idade superior a 40 anos envolvidos com essas espécies. A principal forma de comercialização adotada é a venda direta no varejo $33 \%$, em feiras livres. Na modalidade de uso da terra, foi observado predomínio (66\%) do cultivo em propriedades próprias, familiares e orgânicas.
\end{abstract}

Palavras-chave: Cultura popular; Hortaliças não convencionais; Produção familiar; Produção orgânica; Seguridade alimentar.

\begin{abstract}
Non-conventional food plants (NFP) represent great importance and growing productive potential, with the identification of species in each region being important. In this sense, the objective was to identify and quantify variables that characterize the different species of NFP in the southern region of Minas Gerais. A representative group sample was used with 96 producers selected from 12 associations, covering the period 2018 to 2019. 35 species of PANC produced in a total area of 138 hectares were catalogued, being Yam-Taro (Colocasia esculenta), Leek (Allium porrum), Ora-Pro-Nobis (Pereskia aculeata), Caracara (Dioscorea bulbifera), Pigeon pea (Cajanus cajan), Saffron (Curcuma longa), Ginger (Zingiber officinale), Spinach (Spinacea oleracea), Potato Yacon (Smallanthus sonchifolius), and Serralha (Sonchus oleraceus), the most representative species in the area produced (64\%). The Camponesa association, from Campo do Meio-MG, represented the largest producer of unconventional food plants in the South of Minas Gerais (30\% of the total NFP sold). There was an increasing trend in the number of producers over 40 years old involved with these species. The main form of commercialization adopted is direct retail sales $33 \%$, in open fairs. In the modality of land use, there was a predominance (66\%) of cultivation on own, family and organic properties.
\end{abstract}

Keywords: Popular culture; Unconventional vegetables; Family production; Organic production; Food security. 


\section{Resumen}

Las plantas alimenticias no convencionales (PANC) representan una gran importancia y un potencial productivo creciente, siendo importante la identificación de especies en cada región. En este sentido, el objetivo fue identificar y cuantificar variables que caracterizan los sistemas de producción de diferentes especies de PANC en la región sur de Minas Gerais. Se utilizó una muestra grupal representativa con 96 productores seleccionados de 12 asociaciones, cubriendo el período 2018 a 2019.Se catalogaron 35 especies de PANC producidas en un área total de 138 hectáreas, siendo Yam-Taro (Colocasia esculenta), Puerro (Allium porrum), Ora-Pro-Nobis (Pereskia aculeata), Caracara (Dioscorea bulbifera), Gandul (Cajanus cajan), Azafrán (Curcuma longa), Jengibre (Zingiber officinale), Espinaca (Spinacea oleracea), Yacón de patata (Smallanthus sonchifolius) y Serralha (Sonchus oleraceus), la especie más representativa de la zona producida con estas especies (64\%). La Asociación Campesina, de Campo do Meio-MG, representó el mayor productor de plantas de alimentos no convencionales (30\% del total de PANC vendido). Hubo una tendencia creciente en el número de productores mayores de 40 años involucrados con estas especies. La principal forma de comercialización adoptada es la venta directa al por menor 33\%, en ferias abiertas. En la modalidad de uso de suelo, predominó (66\%) el cultivo en predios propios, familiares y orgánicos.

Palabras clave: Cultura popular; Hortalizas no convencionales; Producción familiar; Producción orgânica; Seguridad alimentaria.

\section{Introdução}

As plantas alimentícias não convencionais (PANC) são definidas como aquelas que possuem uma ou mais partes que podem ser utilizadas na alimentação, in natura ou pela elaboração de produtos derivados, que são pouco comuns no dia a dia da população de uma região ou de um país (Kinupp \& Lorenzi, 2014).

A cultura alimentar que compõe o cardápio atual da alimentação do brasileiro é fundamentada em uma mistura de hábitos advindos do início da colonização do país, com a inserção de grande quantidade de espécies provenientes de diferentes regiões geográficas. Muitas dessas plantas alimentícias foram introduzidas pelos colonizadores e pelos escravos, oriundos de diversas nações, que se estabeleceram no nosso país. Muitas espécies cultivadas se adaptaram bem ao nosso clima e solo, e então começaram a ser cultivadas em maiores escalas agrícolas. Também, uma parte relevante de nossos hábitos alimentares foi herdada dos povos indígenas que habitavam o Brasil antes da colonização, os quais cultivavam espécies alimentares de hortaliças e frutas (Silva et al., 2019; 2021).

A falta de espaço no mercado observada atualmente para as PANC se deve muitas vezes ao sistema de comercialização, que valoriza as plantas convencionais mais comuns, as quais já estão inseridas de forma sólida e são bastante difundidas nos sistemas produtivos de mudas, sementes e insumos diversos. As plantas comestíveis convencionais recebem uma grande divulgação, apoiada no marketing das empresas de sementes. Desta maneira, a população está deixando de conhecer e de consumir várias plantas comestíveis que não estão disponíveis no mercado por não estarem ligadas a pacotes tecnológicos. As PANC apresentam grande potencial em capacidade de geração de renda e de desenvolvimento regional, além de potencial uso gastronômico, não somente em Minas Gerais, mas em todo o território nacional, tornando-as assim de extremo interesse à agricultura familiar (Abras \& Catão, 2018).

A realização de pesquisas que estimulem o uso e a valorização das PANC pode contribuir para a conservação do meio ambiente, para o desenvolvimento sustentável e para o incremento das fontes alimentícias (Biondo et al., 2018; Boedecker et al., 2014; Dutra, 2013; Chaves, 2016; Kinupp e Barros, 2008; Mendes, 2015). Um dos primeiros passos para essas pesquisas deve ser a identificação de populações, hábitos alimentares e as PANC cultivadas em determinadas localidades.

O Estado de Minas Gerais se destaca por sua grande biodiversidade, resultado da diversidade climática, seus solos e seus amplos recursos hídricos, são muitas as espécies vegetais passíveis de serem produzidas no Estado. Visto a grande importância e o potencial crescente para a produção de plantas alimentícias não convencionais no Estado, o trabalho teve como objetivo identificar, quantificar e relacionar variáveis que caracterizem os produtores e as diferentes plantas alimentícias não convencionais produzidas na região Sul de Minas Gerais. 


\section{Metodologia}

A pesquisa utilizou como base a coleta de dados de produtores vinculados a Central de Associações de Produtores Orgânicos - Orgânicos Sul de Minas, que é uma entidade civil sem fins lucrativos, articulada em 2012 por agricultores orgânicos, por meio do Instituto Federal do Sul de Minas, da EMATER-MG e do Ministério da Agricultura (MAPA).

A coleta de dados foi realizada referente ao período de novembro de 2018 a fevereiro de 2019. Os procedimentos metodológicos utilizados na pesquisa envolveram a coleta, a análise e a interpretação destes dados, de acordo com o proposto por Creswell (2009), envolvendo análise de registros dos produtores na associação.

O estudo foi realizado nas associações que têm como sede as cidades de São Lourenço - APOMM, Ouro fino AAOF, Maria da Fé - APAN-FÉ, Poço Fundo-COPFAM, Campo do meio - CAMPONESA, Brasópolis - ABAL e CEABRA, Pedralva - RAMA, Pouso Alegre - ECOMINAS, Três Pontas - RAES, Córrego do Bom Jesus -SERRAS VERDES, Lambari ÁGUAS VIRTUOSAS, e produtores das cidades de Sapucaí-Mirim e Caldas, todas localizadas no Sul de Minas Gerais (Figura 1).

Figura 1. Localização das associações de Produtores Orgânicos do Sul de Minas.

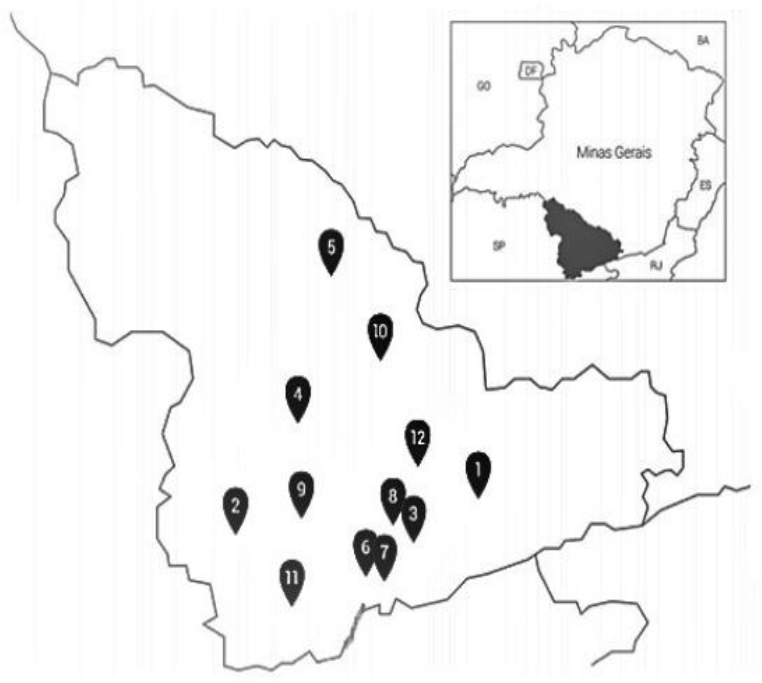

(1) APOMM - São Lourenço-MG

2 AAOF - OURO Fino - MG

(3) APAN-FÉ-Maria da Fé-MG

(4) COOPFAM - Poço Fundo - MG

(5) CAMPONESA - Campo do Meio - MG

6 ABAL - Brasópolis - MG

(7) CEABRA - Brasópolis - MG

8 RAMA - Pedralva - MG

(9) Ecominas - Pouso Alegre - MG

(10 RAES - Três Pontas - MG

(1) Serras Verdes - Córrego do Bom Jesus - MG

(12. Águas Virtuosas - Lambari - MG

Fonte: Autores.

Ao todo as associações contam com 170 associados, dos quais foi utilizada uma amostra de grupo representativo com 96 (noventa e seis) produtores selecionados entre as 12 associações, o que representou 56\% do total de associados. Para o cálculo de tamanho da amostra foi utilizada a fórmula de amostragem sistemática apresentada por Barbetta (2008).

A pesquisa teve caráter de quantificação e de descrição com a finalidade de registrar, analisar e de relacionar as variáveis, com o objetivo de obter o maior número de dados que pudessem ser representativos da produção de PANC no Sul de Minas Gerais. Foram quantificados os dados: idade dos produtores, relação da área total das propriedades, as principais espécies das hortaliças cultivadas, a condição de posse do proprietário (arrendatário ou meeiro), bem como os principais canais de comercialização da produção.

Para a análise e interpretação dos dados foi utilizado o método quantitativo descritivo (Augusto et al., 2013). As informações obtidas foram submetidas à análise estatística descritiva, como ferramenta de organização dos dados. Os dados foram então padronizados a partir do cálculo do tamanho da amostra, baseado na aproximação normal para proporção. Foram 
computadas as frequências absolutas e os percentuais relativos com a finalidade de se extrair as informações das amostras. Os resultados foram expressos em gráficos.

\section{Resultados e Discussão}

A produção de PANC no Sul de Minas Gerais apresentou sólida presença e forte tendência de crescimento. Os maiores percentuais de produção de hortaliças subutilizadas observados foram identificados na associação Camponesa de Campo do Meio, com 32\% do total, seguida da Apan-Fé de Maria da Fé (17\%), Raes de Três Pontas (11\%), Oav de Lambari (8\%), AAOF de Ouro Fino (7\%), Ecominas de Pouso Alegre (6\%), Rama de Pedralva, Apomm de São Lourenço, e Coopfam de Poço Fundo, cada uma representando 5\%, Serras Verdes de Córrego do Bom Jesus (4\%), Ceabra de Brasópolis (1\%), e a Abal também de Brasópolis, onde não foram identificadas PANC (Figura 2).

Figura 2. Representatividade da produção de hortaliças não convencionais dentro das Associações de produtores na região Sul de Minas Gerais (médias entre 2018 e 2019).

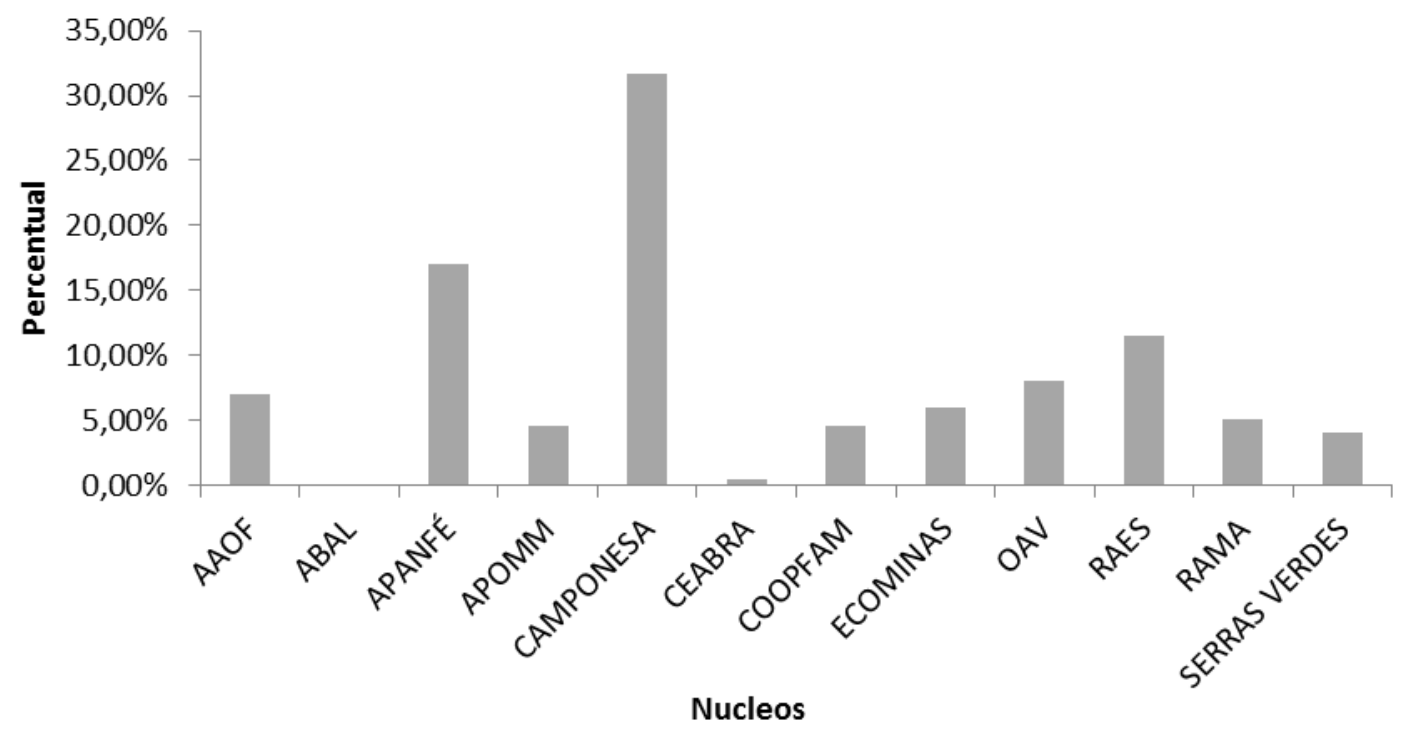

Fonte: Autores.

Foi observado um total de 35 diferentes espécies de PANC comercializadas pelas distintas associações participantes do estudo. A produção de PANC ocupa uma área de aproximadamente 138 hectares de solos cultivados, considerando todas as associações em conjunto.

Na Figura 3 pode ser observada a área destinada para cada uma das espécies cultivadas em 2018 e 2019. Houve um crescimento de 51,5\% da área explorada com PANC considerando todos os produtores participantes do estudo, em 2018 a área destinada para o cultivo de PANC era de 67 ha, já no ano de 2019, a área cultivada foi de 138 ha, o que resultou num aumento de 71 ha. Esse acréscimo pode ser atribuído, principalmente, aos produtores associados à Camponesa, visto que a associação apresentou um aumento de $28 \%$ na comercialização de PANC de 2018 para 2019.

No ano de 2019, as dez principais espécies, ou mais conhecidas, ocuparam 88,6 ha, ou 64,2\% do total da área cultivado por PANC - Inhame-Taro- Colocasia esculenta (16 ha), Alho Poró- Allium porrum (10,76 ha), Ora-Pro-NóbisPereskia aculeata (9,61 ha), Cará-do-ar- Dioscorea bulbifera (8,83 ha), Guandu em grão - Cajanus cajan (8,08 ha), açafrão Curcuma longa (7,70 ha), Gengibre - Zingiber officinale (7,20 ha), Espinafre - Spinacea oleracea (7,10 ha), Batata Yacon - 
Smallanthus sonchifolius (6,86 ha), Serralha- Sonchus oleraceus (6,44 ha).

As outras 25 espécies levantadas foram cultivadas em 35,8 \% da área no ano de 2019, o que representa 49,4 ha (média por hortaliça $=1,97 \mathrm{ha}$, máx $=6$ ha e $\min =0,02$ ha), sendo distribuídas em: Taioba - Xanthossoma sp $(6,00$ ha $)$, Coentro Coriandrum sativum (5,55 ha), Agrião - Nasturtium officinale (4,92 ha), Urucum - Bixa orellana, (4,45 ha), Fava - Vicia faba (3,72 ha), Mostarda- Brassica nigra (3,53 ha), Gergelim - Sesamum indicum (3,02 ha), Cúrcuma- Curcuma longa (2,62 ha), Physalis - Physalis peruviana (2,08 ha), Bucha - Luffa aegyptiaca (2,02 ha), Azedinha - Rumex acetosa (1,66 ha) Maxixe Cucumis anguria (1,62 ha), Alcachofra - Cynara scolymus (1,50 ha), Beldroega - Portulaca oleracea (1,50 ha), Caruru Amaranthus spp. (1,50 ha), Cabaça -Lagenaria siceraria (1,02 ha), Aipo - Apium graveolens (1,02 ha), Cavalinha -Equisetum (0,51 ha), Nira - Allium macrostemon (0,50 ha), Linhaça - Linum usitatissimum L. (0,06 ha), Peixinho - Stachys spp, (0,02 ha), Grão-de-bico - Cicer arietinum (2,45 ha), Orégano - Origanum vulgare (2,22 ha), e Manjericão - Ocimum basilicum (1,70 ha).

Figura 3. Áreas (em hectares) de PANC produzidas no Sul de Minas Gerais.

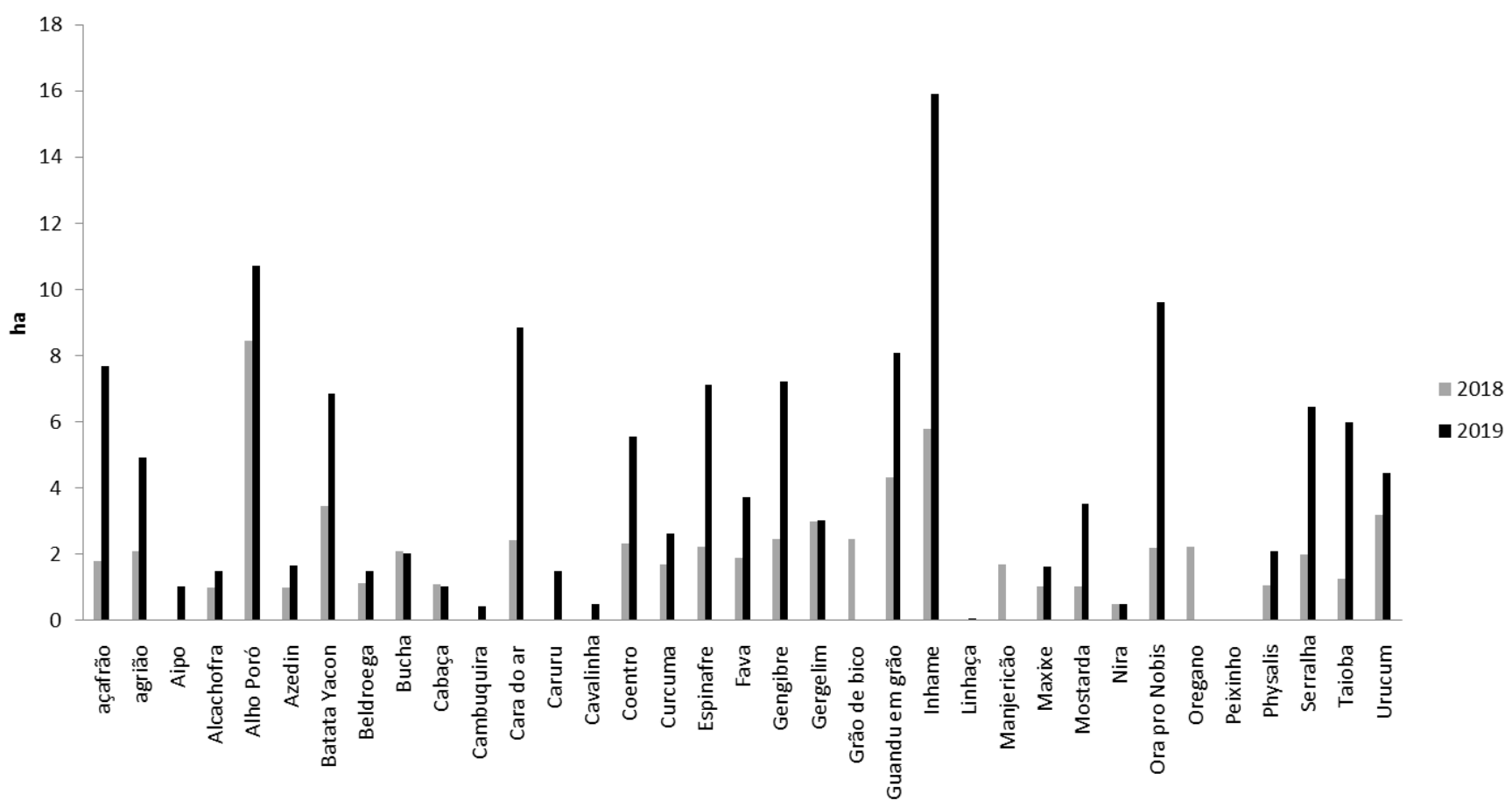

Fonte: Autores.

O aumento de 71 ha entre os anos de 2018 para 2019, chegando a 138 ha destinados a produção de PANC em 2019, denota a importância socioeconômica que essas espécies representam para a região, bem como para todo o Estado de Minas Gerais. De acordo com Silva et al., 2018, estas hortaliças são representativas em determinadas regiões e em culturas alimentares do Estado, além de serem importantes em segmentos como alimentar, ambiental, socioeconômico, entre outros.

Para o levantamento do perfil do produtor de PANC do Sul de Minas Gerais foi avaliada a variável da idade do produtor, pois a mesma pode estar ligada a tradição e a cultura na produção das espécies. Foi observado aumento no cultivo de PANC em produtores maiores de 41 anos, comparando os anos de 2018 a 2019 (Figura 4). 
Figura 4. Percentuais das idades dos produtores que trabalham com PANC no Sul de Minas Gerais.

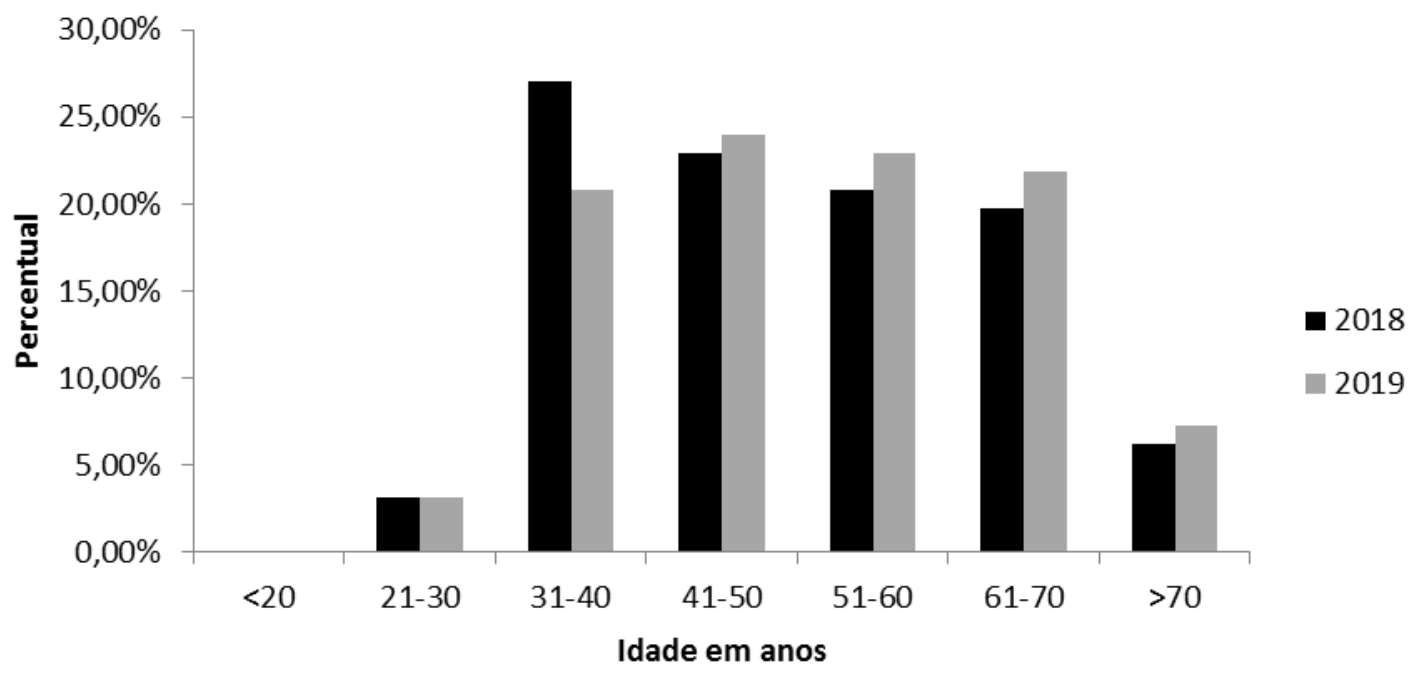

Fonte: Autores.

Entre os anos de 2018 e 2019 houve uma tendência de redução no número de produtores jovens, com idades inferiores a 40 anos, enquanto que se observa certa tendência de aumento no número de produtores com idades superiores a 40 anos. Silva et al. (2015) observaram tendência similar em sua pesquisa com os produtores de hortaliças da região metropolitana de Belo Horizonte, Estado de Minas Gerias. A produção das PANC está intimamente relacionada com o resgate de antigos hábitos culturais e alimentares, que já foram comuns e convencionais em outros tempos. Agricultores mais velhos comumente reconhecem a maioria das PANC e o potencial de seus usos, entretanto, novos agricultores gradativamente estão incorporando as PANC no sistema produtivo.

A produção das PANC resiste principalmente devido aos costumes e às culturas alimentares de algumas populações, que geralmente se encontram em um número restrito de localidades geográficas do Estado. Comumente estas plantas são desconhecidas pela maioria dos novos profissionais e pelos novos produtores agrícolas, pois, normalmente, são reconhecidas como plantas invasoras ou "daninhas". Por isso, existe atualmente uma grande demanda por informações, resgate, estudos e produção das PANC nos mais variados segmentos da sociedade. Isto favorece o resgate destas espécies de planta, destacando a sua importância nos segmentos ambiental, alimentar, socioeconômico, cultural, entre outros.

Desta forma, torna-se evidente a necessidade de difundir mais informações relativas às PANC para os agricultores, destacando as técnicas filotécnicas de propagação, produção de mudas e do manejo da produção agrícola, bem como a correta identificação botânica, formas de utilização e de preparo, para que assim se potencialize a produção e a diversificação da alimentação diária dessas populações (Terra \& Ferreira, 2020).

O principal canal de comercialização utilizado pelas associações de produtores foi diretamente ao consumidor (33\%), seguido pela venda no mercado varejista do CEASA (24\%) e mercado atacadistas (20\%), e outros canais de venda representaram 18\% (hotéis, restaurantes, feiras, outras associações) (Figura 5). Estes resultados corroboram Silva et al (2015) que ao avaliarem a comercialização de hortaliças produzidas no cinturão da região metropolitana de BH também observaram a venda direto ao consumidor como principal canal de venda.

Estes resultados podem estar relacionados à característica de alta perecibilidade das hortaliças, fato que exige um arranjo de canal de distribuição que permita sua comercialização eficiente, o que está, muitas vezes, fora do alcance dos produtores. Contudo, essa forma de comercialização caracteriza o pequeno produtor, fazendo com que haja uma proximidade com o consumidor. 
Figura 5. Percentuais médios dos canais de comercialização das hortaliças não convencionais no Sul de Minas Gerais (2018 e 2019).

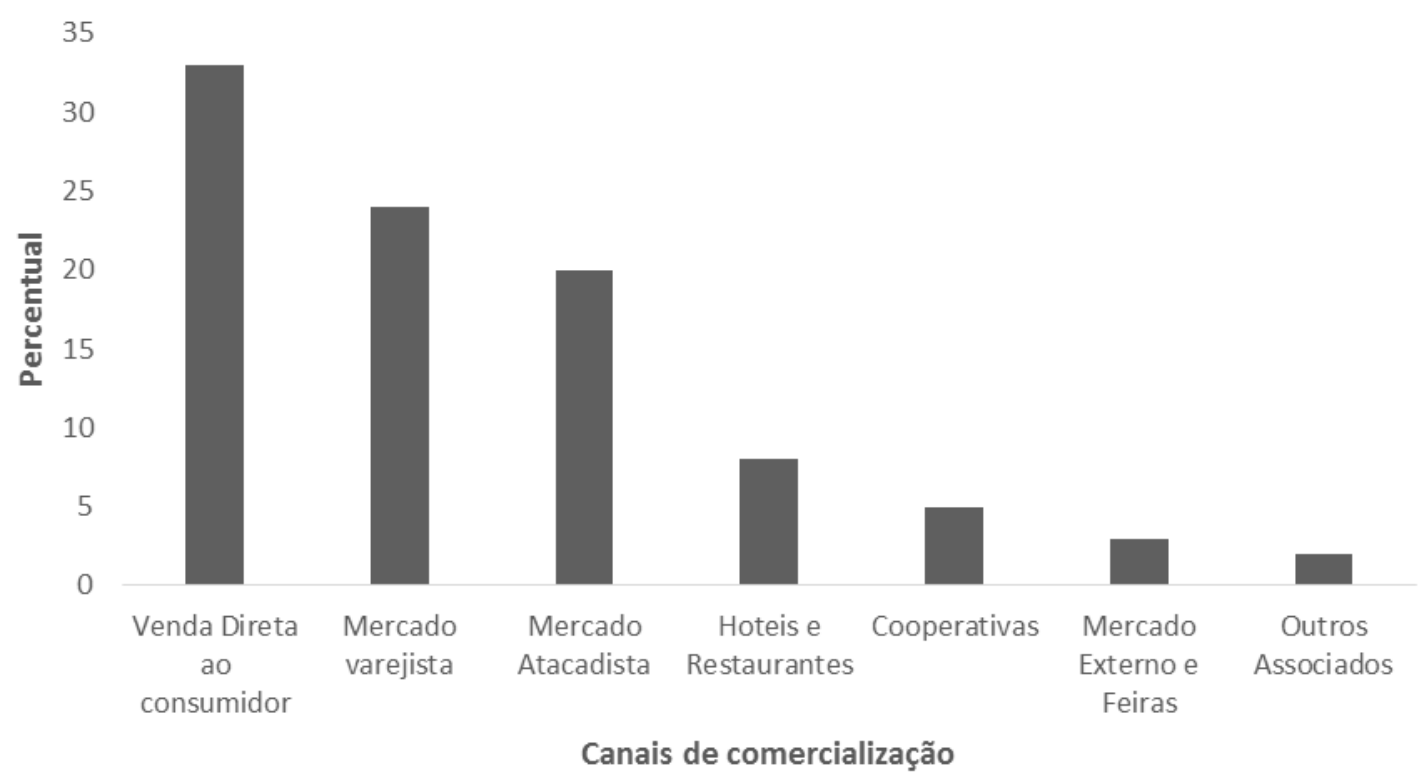

Fonte: Autores.

Dias-Netto et al. (2019), em seu diagnóstico sobre a produção de hortaliças orgânicas das associaç̃oes de agricultura familiar do Sul de Minas Gerais, também concluiu que a forma de comercialização mais utilizada foi a venda direta ao consumidor. As vendas diretas ao consumidor promovem um estreitamento da relação entre consumidores e produtores, o que potencializa a proposta de uma agricultura familiar e/ou orgânica mais sustentável (Sousa et al., 2012)

A comercialização das PANC nas feiras agroecológicas é importante para auxiliar na difusão deste tipo de mercado e estimular as pessoas na valorização dos alimentos orgânicos e das PANC, além de reconhecer e favorecer a relevância do trabalho do agricultor familiar (de F. Padilha et al., 2020).

Para a modalidade de uso da terra dos produtores das PANC, foi observado predomínio do cultivo em propriedades próprias $(65,6 \%)$, seguido por áreas arrendadas $(21,88 \%)$, assentamento de reforma agrária $(5,21 \%)$ e outras modalidades como meeiros e comodatários $(7,28 \%)$ (Figura 6). As propriedades levantadas tinham caracterização de sistemas familiares e orgânicos.

O agricultor familiar do ponto de vista legal (Lei ${ }^{\circ} 11.326$ de 2006) é aquele que pratica atividades no meio rural e cumpre os seguintes quesitos: I - não deter área maior que quatro módulos fiscais; II - utilizar predominantemente mão de obra da própria família nas atividades de seu estabelecimento ou empreendimento; III - a renda familiar ser predominantemente originada de atividades vinculadas ao próprio estabelecimento e IV - o estabelecimento ser dirigido pelo agricultor (a) com sua família (art.3) (Guanziroli, 2012).

De acordo com Abras e Catão (2018) propriedades caracterizadas como familiares são aquelas onde os membros da família vivem na propriedade e a gestão é feita pelos proprietários da unidade familiar. 
Figura 6. Modalidade de uso da terra para produção das PANC no Sul de Minas Gerais.

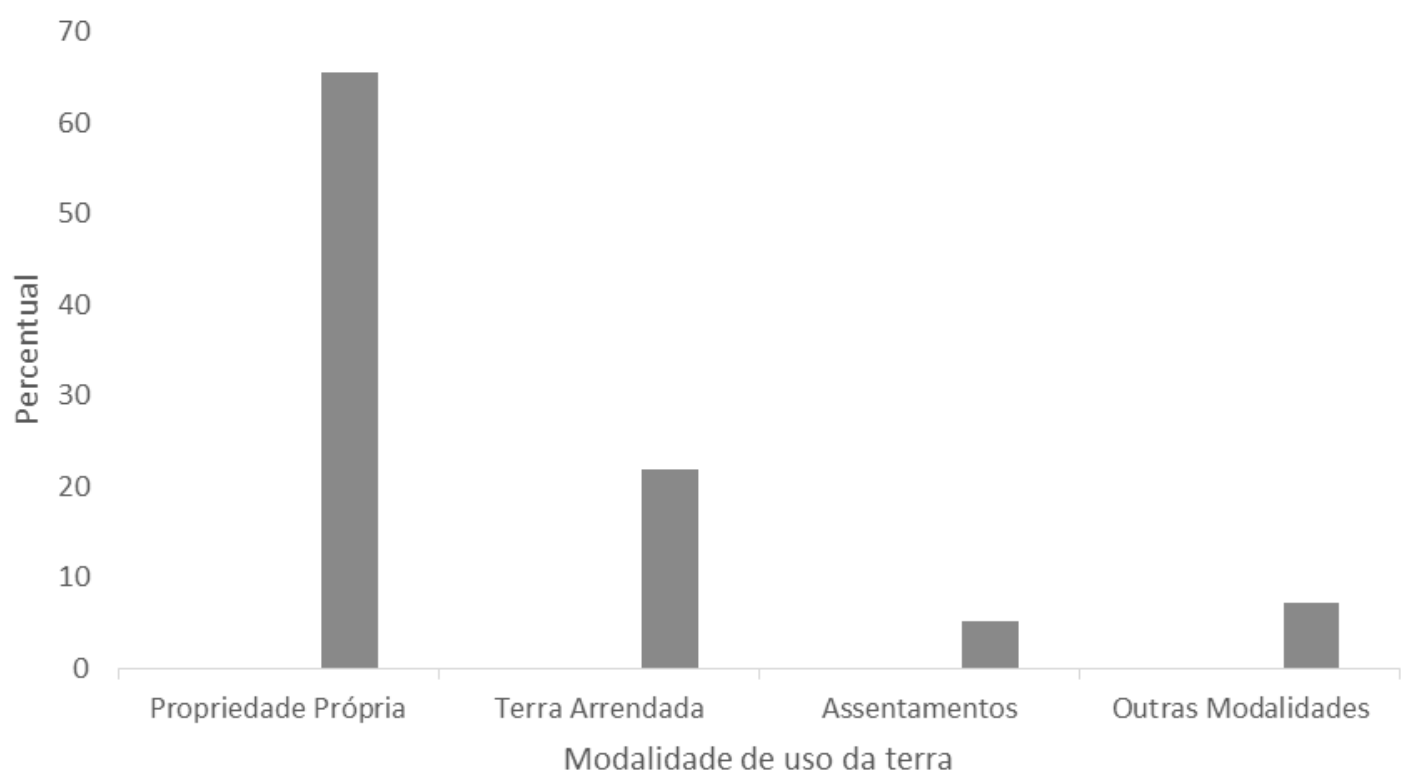

Fonte: Autores.

Esses resultados corroboram os obtidos por Feijó (2010), que constatou que os produtores familiares e orgânicos se concentram, em sua maioria, em pequenas propriedades próprias. Situações similares são observadas em assentamentos, muitas vezes estimulados por movimentos de reforma agrária.

\section{Conclusão}

As plantas alimentícias não convencionais têm marcante presença e apresentam expansão no comercio da região Sul de Minas Gerais, sendo Inhame-Taro- Colocasia esculenta, Alho Poró- Allium porrum, Ora-Pro-Nóbis- Pereskia aculeata, Cará-do-ar- Dioscorea bulbifera, Guandu em grão - Cajanus cajan, açafrão - Curcuma longa, Gengibre - Zingiber officinale, Espinafre - Spinacea oleracea, Batata Yacon - Smallanthus sonchifolius, e Serralha- Sonchus oleraceus, as mais representativas. Há uma tendência de redução no número de produtores jovens que trabalham com essas espécies, enquanto que se observa certa tendência de aumento no número de produtores com idade superior a 40 anos. A principal forma de comercialização adotada é a venda direta no varejo 33\%, em feiras livres. Na modalidade de uso da terra, foi observado predomínio (66\%) do cultivo em propriedades próprias, sendo caracterizadas como de agricultura familiar e orgânica.

\section{Agradecimentos}

Os autores agradecem o apoio da Coordenação de Aperfeiçoamento de Pessoal de Nível Superior - Brasil (CAPES) e da Universidade José do Rosário Vellano, Alfenas, Brasil.

\section{Referências}

Abras, M., \& Catão, L. (2018). Agricultura familiar como agente de desenvolvimento regional por meio do cultivo e comercialização de hortaliças não convencionais em Minas Gerais. Cadernos de Agroecologia, 13(1).

Augusto, C. A., Souza, J. P. D., Dellagnelo, E. H. L., \& Cario, S. A. F. (2013). Pesquisa Qualitativa: rigor metodológico no tratamento da teoria dos custos de transação em artigos apresentados nos congressos da Sober (2007-2011). Revista de Economia e Sociologia Rural, 51(4), 745-764.

Barbetta, P. A. (2008). Estatística aplicada às ciências sociais. Ed. UFSC. 
Boedecker, J., Termote, C., Assogbadjo, A. E., Van Damme, P., \& Lachat, C. (2014). Dietary contribution of Wild Edible Plants to women's diets in the buffer zone around the Lama forest, Benin-an underutilized potential. Food Security, 6(6), 833-849.

Biondo, E., Fleck, M., Kolchinski, E. M., Voltaire, S. A., \& Polesi, R. G. (2018). Diversidade e potencial de utilização de plantas alimentícias não convencionais no Vale do Taquari, RS. Revista Eletrônica Científica da UERGS, 4(1), 61-90.

Chaves, M. S. (2016). Plantas alimentícias não convencionais em comunidades ribeirinhas na Amazônia.

Creswell, J. W. (2009). Mapping the field of mixed methods research. Journal of mixed methods research, 3(2), 95-108.

De Fátima Padilha, M. D. R., do Nascimento Souza, V. B., Shinohara, N. K. S., \& de Mendonça Pimentel, R. M. (2020). Plantas Alimentícias Não Convencionais presentes em Feiras Agroecológicas em Recife: Potencial Alimentício. Brazilian Journal of Development, 6(9), 64928-64940.

Dias Netto, E. S; Marques, D. J; Bianchini, H. C. (2020). Diagnóstico da produção de hortaliças orgânicas das associações da agricultura familiar do Sul de Minas Gerais. Cadernos de Ciência \& Tecnologia, 37(1), 1-9.

Diegues, A. C. S. A. (2001). O mito moderno da natureza intocada (Vol. 4). Hucitec.

Dutra, L. V. (2013) Insegurança alimentar e nutricional e produção para o autoconsumo na zona rural de São Miguel do Anta, Minas Gerais. 118 f. Dissertação (Mestrado em Agroecologia) Universidade Federal de Viçosa, 2013.

Feijó, R. L. C. (2010). O efeito do título de propriedade da terra na determinação da renda rural. Revista de Economia e Sociologia Rural, 48, 673-707.

Guanziroli, C. E., Buainain, A. M., \& Di Sabbato, A. (2012). Dez anos de evolução da agricultura familiar no Brasil: (1996 e 2006). Revista de Economia e Sociologia Rural, 50(2), 351-370.

Kinupp, V. F. \& Lorenzi, H. J. (2014). Plantas Alimentícias Não Convencionais (PANC) no Brasil: guia de identificação, aspectos nutricionais e receitas ilustradas.

Kinupp, V. F. \& Barros, I. B. I. (2008). Teores de proteína e minerais de espécies nativas, potenciais hortaliças e frutas. Ciência Tecnologia Alimentos, [S.1.], v.28, n.4, p.846-857.

Mendes R. J. S. (2015). Biodiversidade e composição de alimentos: dados nutricionais de frutas nativas subutilizadas da flora brasileira. 111f. Dissertação (Mestrado em Ciências) - Universidade de São Paulo, São Paulo.

Nitzke, J. A., Thys, R., Martinelli, S., Oliveiras, L. Y., Augusto-Ruiz, W., Penna, N. G., \& Noll, I. B. (2012). Segurança alimentar: retorno às origens? Brazilian Journal of Food Technology, 15, 02-10.

Silva, W. F., Marques, D. J., Silva, E. C., Bianchini, H. C., Ishimoto, F. A., \& Pereira, M. J. (2015). Diagnóstico da produção de hortaliças na região metropolitana de Belo Horizonte. Revista Horticultura Brasileira, 33, 368-372.

Silva, L. F. L. E., Souza, D. C., Resende, L. V., Nassur, R. D. C. M., Samartini, C. Q., \& Gonçalves, W. M. (2018). Nutritional evaluation of non-conventional vegetables in Brazil. Anais da Academia Brasileira de Ciências, 90, 1775-1787.

Silva, L. F. L., de Souza, D. C., Xavier, J. B., Samartini, C. Q., \& Resende, L. V. (2019). Avaliação nutricional de caruru (Amaranthus spp). Agrarian, 12(45), 411-417.

Silva, L. F. L. E., Souza, D. C. D., Nassur, R. D. C. M. R., Bittencourt, W. J. M., Resende, L. V., \& Gonçalves, W. M. (2021). Nutritional characterisation and grouping of unconventional vegetables in Brazil. The Journal of Horticultural Science and Biotechnology, 96(4), 508-513.

Sousa, A. A. D., Azevedo, E. D., Lima, E. E. D., \& Silva, A. P. F. D. (2012). Alimentos orgânicos e saúde humana: estudo sobre as controvérsias. Revista Panamericana de Salud Publica, 31, 513-517.

Terra, S. B., \& Ferreira, B. P. (2020). Conhecimento de plantas alimentícias não convencionais em assentamentos rurais. Revista Verde de Agroecologia e Desenvolvimento Sustentável, 15(2), 221-228. 